\title{
Is nasogastric suction necessary in acute pancreatitis?
}

\author{
R NAEIJE, E SALINGRET, N CLUMECK, A DE TROYER, G DEVIS
}

British Medical fournal, 1978, 2, 659-660

\section{Summary and conclusions}

Fifty-eight patients with mild to moderately severe acute pancreatitis were randomly allocated to treatment with or without nasogastric suction $(27$ and 31 patients respectively). Intravenous fluids and pethidine hydrochloride were also given. The two groups were comparable clinically at the start of the study. There were no differences between the two groups in the mean duration of the following features: abdominal pain or tenderness; absence of bowel movements; raised serum amylase concentration; time to resumption of oral feeding; and days in hospital. Prolonged hyperamylasaemia (serum amylase $>0.33 \mathrm{mU} / \mathbf{1}$ ) occurred in one patient in the suction group and in three patients in the non-suction group. $A$ mild recurrence of abdominal pain after resumption of oral feeding occurred in three patients in the suction group and in two patients in the non-suction group. Two patients in the suction group developed overt consumption coagulopathy and two others pulmonary complications. No patient in the non-suction group had complications.

The findings suggest that most patients with mild to moderately severe acute pancreatitis do not benefit from nasogastric suction. The procedure should be elective rather than mandatory in treating this condition.

\section{Introduction}

Nasogastric suction is traditionally recommended in the treatment of acute pancreatitis ${ }^{1}$ to prevent gastric contents passing into the duodenum and so to inhibit the formation of intestinal hormones that stimulate the pancreas. Various methods of suppressing pancreatic secretion have been devised, but their therapeutic value has not been established. ${ }^{2}$ In two recent randomised studies on patients with acute alcoholic pancreatitis omission of nasogastric suction did not affect outcome. ${ }^{34}$

We evaluated the effectiveness of nasogastric suction in 58 patients with mild to moderately severe acute pancreatitis of various aetiologies.

\section{Patients and methods}

Fifty-eight patients with clinical features of acute pancreatitis and raised serum and urinary amylase concentrations were studied. None of them was in shock, coma, or presented with renal insufficiency. No patient with active peptic ulcer, perforated viscus, intestinal obstruction, ureteral calculi, or intra-abdominal abscess was included. Exploratory laparotomy was not carried out. All patients gave informed consent to participating in the study.

Department of Internal Medicine, Saint-Pierre University Hospital, B - 1000 Brussels, Belgium

R NAEIJE, MD, assistant

E SALINGRET, nurse

N CLUMECK, MD, assistant

A DE TROYER, MD, assistant

Department of Gastroenterology, VUB University Hospital, B - 1090 Brussels, Belgium

G DEVIS, MD, PHD, head of department
The following data were obtained for all patients on admission: history and results of clinical examination; standard $x$-ray pictures of chest and abdomen; electrocardiogram; estimations of blood concentrations of urea, creatinine, urate, sodium, potassium, chloride, bicarbonate, calcium, glucose, triglycerides, and amylase; complete blood count; results of liver function tests; results of urine analysis; estimations of urinary concentrations of amylase and creatinine. On the day of admission patients were randomly allocated to treatment with or without nasogastric suction. Nothing was given by mouth to those without gastric tube. All patients received intravenous fluids and electrolytes and intramuscular pethidine hydrochloride as required. Oral feeding was resumed as soon as the patient was symptomless and the serum amylase concentration was normal, or, if hyperamylasaemia persisted, as soon as the patient had been symptomless for four days.

Between 8 and 12 am every day until feeding was resumed each patient was examined, his symptoms were recorded, and blood was obtained for estimations of urea, creatinine, sodium, potassium, chloride, bicarbonate, calcium, fibrinogen, and amylase concentrations and complete blood count. After the acute phase of pancreatitis had resolved, an oral cholecystogram was performed. If the aetiology of acute pancreatitis was unclear or if chronic pancreatitis was suspected endoscopic retrograde pancreatography, ultrasonography, and pancreatic function tests were performed.

Alcoholism was defined as a daily consumption of at least 2 litres of beer or an equivalent quantity of alcohol. Gall-bladder disease was considered to be the cause of pancreatitis when gall stones could be shown. Amylase was measured by iodometry ${ }^{5}$ (upper limit of normal $0.33 \mathrm{mU} / \mathrm{l})$. The amylase :creatinine clearance ratio (Cam:Ccr) was calculated by use of a standard method ${ }^{6}$ (upper limit of normal for our laboratory $5 \%$ ). Student's $t$ test was used in statistical analyses.

\section{Results}

Details of patients in the two treatment groups are compared in table I. No significant difference was observed in any category, except for Cam:Ccr, which was lower in those who had not undergone nasogastric suction $(P<0.05)$. The following findings were negative

TABLE I-Clinical details and laboratory findings on admission in 58 patients with acute pancreatitis who were randomly allocated to receive treatment with or without nasogastric suction. Values are means $\pm S E$ of mean

\begin{tabular}{|c|c|c|c|}
\hline & \multicolumn{2}{|c|}{ Treatment group } & \multirow[b]{2}{*}{$\mathbf{P}$} \\
\hline & Suction & No suction & \\
\hline $\begin{array}{l}\text { No of patients } \\
\text { Sex } \\
\text { Age (years) } \\
\text { Amylase }(\mathrm{mU} / \mathrm{l}) \\
\text { Cam: Ccr }(\%) \\
\text { White cell count }\left(10^{9} / \mathrm{l}\right) \\
\text { Total bilirubin }(\mu \mathrm{mol} / \mathrm{l})\end{array}$ & $\begin{array}{c}27 \\
20 M ; 7 \mathrm{~F} \\
44 \pm 2 \cdot 5 \\
3 \cdot 04 \pm 0 \cdot 51 \\
8 \cdot 4 \pm 1 \cdot 3 \\
12 \cdot 9 \pm 1 \\
25 \cdot 5 \pm 5 \cdot 1\end{array}$ & $\begin{array}{c}31 \\
19 M ; 12 F \\
41 \pm 2 \cdot 2 \\
2 \cdot 95 \pm 0 \cdot 52 \\
5 \cdot 7 \pm 0.5 \\
11 \pm 0.9 \\
23 \cdot 8 \pm 3 \cdot 4\end{array}$ & $\begin{array}{l}\text { NS } \\
\text { NS } \\
<0.05 \\
\text { NS } \\
\text { NS }\end{array}$ \\
\hline
\end{tabular}

NS $=$ Not significant.
Conversion: SI to traditional units-Serum bilirubin: $1 \mu \mathrm{mol} / 1 \approx 0.06 \mathrm{mg} / 100 \mathrm{ml}$.

in all patients on admission: pulse rate $>120 / \mathrm{min}$; fever $>38.5^{\circ} \mathrm{C}$; clinical abnormalities of lung fields; palpable abdominal mass; serum albumin concentration $<30 \mathrm{~g} / \mathrm{l}$; serum calcium concentration $<2 \mathrm{mmol} / 1(8 \mathrm{mg} / 100 \mathrm{ml})$; prothrombin time $>14 \mathrm{~s}$; packed cell volume $<0.30(<30 \%)$; abnormalities on chest $x$-ray pictures. Two patients in the suction group and two patients in the non-suction group presented with a white cell count $>20 \times 10^{9} / 1\left(>20000 / \mathrm{mm}^{3}\right)$, the highest recorded value being $23 \times 10^{9} / 1$. One patient in the suction group and three in the non-suction group had a serum bilirubin concentration $>108.4 \mu \mathrm{mol} / 1(4 \mathrm{mg} / 100 \mathrm{ml})$, the highest recorded value being $133.4 \mu \mathrm{mol} / 1(7.8 \mathrm{mg} / 100 \mathrm{ml})$. Thus no patient had a combination of symptoms, signs, and laboratory findings that would have adversely affected prognosis. ${ }^{7}$ None of the patients died. 
Table II shows aetiological factors leading to acute pancreatitis in the two patient groups. Acute relapsing alcoholism was distributed fairly evenly in both groups, and had a better prognosis than the other categories. The mean duration of various clinical features did not differ significantly in the two groups of patients (table III). Prolonged ( $>10$ days) hyperamylasaemia occurred in three patients in the nonsuction group and one in the suction group. The cause was an impacted stone in the common bile duct, which was surgically removed in two of the patients in the non-suction group and in the single patient in the suction group. Transient recurrence of abdominal pain after oral feeding was resumed occurred in three patients in the suction group and in one patient in the non-suction group. No complications were observed in the non-suction group. In the suction group one patient developed a left basal pneumonia on the second day in hospital, another a right pleural effusion on the fourth day, and two others an overt consumption coagulopathy. These complications were not apparently related to the presence of the nasogastric tube.

TABLE II-Aetiology of acute pancreatitis in 58 patients who were randomly allocated to receive treatment with or without nasogastric suction

\begin{tabular}{l|c|c}
\hline \multirow{2}{*}{ Aetiological factor } & \multicolumn{2}{|c}{ Treatment group } \\
\cline { 2 - 3 } & Suction & No suction \\
\hline Acute alcoholism & 5 & 7 \\
Acute relapsing alcoholism & 7 & 6 \\
Chronic relapsing alcoholism & 3 & 2 \\
Gall-bladder disease & 3 & 13 \\
Unknown & 3 & 3 \\
\hline
\end{tabular}

TABLE III-Mean ( $\pm S E$ of mean) duration in days of clinical features of mild to moderately severe acute pancreatitis in patients who received treatment with or without nasogastric suction (27 and 31 patients respectively)

\begin{tabular}{l|c|c|c}
\hline \multirow{2}{*}{ Clinical features } & \multicolumn{2}{|c|}{ Treatment group } & \\
\cline { 2 - 3 } & Suction & No suction & P \\
\hline Abdominal pain & $3 \pm 0.3$ & $2.5 \pm 0 \cdot 2$ & NS \\
Abdominal tenderness & $3.5 \pm 0.3$ & $2 \cdot 9 \pm 0 \cdot 2$ & NS \\
No bowel movement & $2 \cdot 6 \pm 0.3$ & $2 \cdot 4 \pm 0 \cdot 2$ & NS \\
Raised serum amylase concentration & $3 \pm 0 \cdot 25$ & $3 \cdot 6 \pm 0 \cdot 4$ & NS \\
No food by mouth & $3.9 \pm 0.3$ & $3.9 \pm 0 \cdot 1$ & NS \\
Hospitalisation & $11 \pm 0.9$ & $9 \pm 0.9$ & NS \\
& & &
\end{tabular}

NS $=$ Not significant

\section{Discussion}

Our study shows that omission of nasogastric suction does not affect outcome in patients with mild to moderately severe acute pancreatitis of differing aetiologies. This confirms the findings of reports on alcoholic patients. ${ }^{34}$

In treating acute pancreatitis the pancreas is traditionally "rested" to prevent autodigestion of the gland and limit the inflammatory process. ${ }^{1}$ Nevertheless, pancreatic autodigestion, though plausible, remains an unproved hypothesis. ${ }^{2}$ Moreover, all experimental evidence suggests that the pancreas is fully "shut down" during the acute phase of the disease. ${ }^{8}$ This is presumably why no treatment designed to suppress pancreatic secretion has yet been shown to be useful. ${ }^{2}$

Patients with acute pancreatitis (even when the condition is considered to be mild) feel ill and do not appreciate the additional discomfort of gastric suction. The presence of a tube in the oesophageal sphincters may even be harmful, since it is associated with an increased risk of aspiration pneumonia. ${ }^{9}$ Nasogastric suction is clearly indicated when duodenal obstruction or paralytic ileus develop. It may sometimes help in relieving vomiting: nevertheless, most of our patients vomited on admission but stopped within a few hours, whether a tube was passed or not. We consider that nasogastric suction should be an elective rather than mandatory procedure in the treatment of mild to moderately severe acute pancreatitis.

\section{References}

1 Ammann, R, in Gastroenterology, ed H L Bockus, vol 3. Philadelphia, W B Saunders, 1976.

${ }^{2}$ Soergel, K H, Gastroenterology, 1978, 74, 620.

${ }^{3}$ Levant, J A, et al, fournal of the American Medical Association, 1974, 229, 51.

${ }^{4}$ Switz, D M, Vlahcevic, Z R, and Farrar, J T, Gastroenterology, 1975, 68, 994.

5 Street, H V, and Close, J R, Clinica Chimica Acta, 1956, 1, 256.

${ }^{6}$ Levitt, M D, Rapoport, M, and Cooperband, S R, Annals of Internal Medicine, 1969, 71, 919.

7 Jacobs, M L, et al, Annals of Surgery, 1977, 185, 43.

${ }^{8}$ Dreiling, D A, Fournal of the American Medical Association, 1961, 175, 105.

- Cameron, J L, and Zuidema, G D, fournal of the American Medical Association, 1972, 219, 1194.

(Accepted 14 fuly 1978)
ONE HUNDRED YEARS AGO If it were not fraught with a multitude of calamitous incidents, a true narrative of the sanitary movement in Calcutta during the last fifteen years would amusingly illustrate the grim tenacity with which people generally cling to their ancestral filth. About three years ago, the municipality discovered that they had arrived at the conclusion that the appointment of a scientific physician as their officer of health was an experiment worth trying; and since then Dr Payne has steadily endeavoured to sanitate in a hopelessly insanitary city, striving manfully against a host of natural and artificial difficulties, amongst which are a soil absolutely saturated with the collected impurities of two hundred years, an atmosphere laden with marsh-poison, an utterly untrustworthy system of registration, scanty means, and steady opposition. Nevertheless, on taking charge, he found that something had been done in the right direction: the city had received a good supply of drinking water, a large system of underground drainage was being extended from the European to the native quarter of the town, and scavenging was systematically at work. Since then, his reports show that he is intent upon the measure of obliterating the indescribably foul private tanks and wells out of which the natives continue to drink, regardless of the fair water which has been brought to their very doors. Take the horse-pond contiguous to the farmyard of the worst managed farm in the United Kingdom; suppose its water to have been originally brackish; let the entire excreta of the house be led into it; request the inhabitants to smear their bodies daily with glue or mustard-oil, and to wash themselves and their cotton-garments as often in its waters; imagine these waters to have become "thick and slab" during five months of perfectly dry weather; again, take it almost for granted that cholera stools form an item in the compound,-and you may begin to understand what a private Calcutta tank affords its proprietor in the way of drinking water at the setting in of the cholera season at the beginning of the hot weather in March. To one who has to deal with one of these tanks, it is immaterial whether Dr Pettenkofer be right in arguing that cholera is influenced by fluctuations in the water-level of a polluted subsoil, or whether Virchow be correct in looking for the poison of cholera in the water itself. Here common sense bids science stand aside and argue out the question while workmen are shovelling earth into this very plague-spot, the undisputed fons et origo mali. We are sorry to see that Dr Payne speaks of "gathering the refuse of the whole town" for the purpose of filling condemned tanks and wells. True that, in a country which is as level as a billiard-table, very little clean material is available for this purpose, with the exception of the debris of old brick buildings, of which the supply is very limited. Still, the calamitous history of the Bamun Bustee houses (mansions built upon made ground over what was once a tank in Sir Elijah Impey's grounds, and in which cholera has repeatedly shown itself almost up to the present day) should make us very careful how we fill up tanks with sewage-silt and then build upon their sites. The report before us gives the cholera deaths in the months of July, August, and September from the year 1868. In considering these, it must be borne in mind that endemic cholera is never absent from Calcutta; it slays some victims daily, and, between the setting in of the hot season, about the middle of March, and the commencement of the rains, in the third or fourth week of June, it rages as a pestilence. (British Medical fournal, 1878.) 